\title{
Taxonomic re-evaluation of the Taiwanese montane earthworm Amynthas wulinensis Tsai, Shen \& Tsai, 2001 (Oligochaeta: Megascolecidae): Polytypic species or species complex?
}

\author{
Chih-Han Chang ${ }^{\mathrm{a}}$, Yu-Hsung Lin ${ }^{\mathrm{b}}$, I.-Han Chen ${ }^{\mathrm{b}}$, Shu-Chun Chuang ${ }^{\mathrm{b}}$, \\ Jiun-Hong Chen ${ }^{\mathrm{a}, \mathrm{b}, *}$ \\ anstitute of Zoology, National Taiwan University, No. 1, Sec. 4, Roosevelt Road, Taipei 106, Taiwan, ROC \\ ${ }^{\mathrm{b}}$ Department of Life Science, National Taiwan University, No. 1, Sec. 4, Roosevelt Road, Taipei 106, Taiwan, ROC
}

Received 26 October 2005; accepted 30 June 2006

\begin{abstract}
Body size and colouration are two characters commonly used in the taxonomy of many animal taxa. However, they are seldom used by earthworm taxonomists because they are subject to environmental influences and tend to vary intraspecifically. In the present study, DNA sequences of the mitochondrial COI gene are used to evaluate whether specimens of the megascolecid earthworm Amynthas wulinensis Tsai, Shen \& Tsai, 2001 that differ in body size and/or colouration belong to different genetic lineages. Phylogenetic analyses and morphological comparisons indicate that A. wulinensis in the previous broad sense is a species complex composed of three species differing in body size, colouration, and genital markings. Consequently, two new species, Amynthas lini and Amynthas meishanensis, are described. Taxonomic affinities of the $A$. wulinensis species complex are discussed, as is the feasibility of using body size and colouration in earthworm taxonomy.
\end{abstract}

(C) 2007 Gesellschaft für Biologische Systematik. Published by Elsevier GmbH. All rights reserved.

Keywords: Amynthas wulinensis; A. lini; A. meishanensis; New species; Phylogeny; Megascolecidae

\section{Introduction}

Morphological characters, both quantitative and qualitative, are used by morphological taxonomists for species identification. In earthworm systematics, reproductive organs, including the clitella, male pores, female pores, testes, ovaries, spermathecae, and prostate glands, are given the greatest importance, as these characters are believed to be less affected by environ-

\footnotetext{
${ }^{*}$ Corresponding author. Institute of Zoology, National Taiwan University, No. 1, Sec. 4, Roosevelt Road, Taipei 106, Taiwan, ROC. Tel.: + 886233662502 ; fax: +886223658912 .

E-mail address: chenjh@ntu.edu.tw (J.-H. Chen).
}

mental fluctuations through time, and are evolutionarily more conservative. Other characters used by earthworm taxonomists include some anatomical features, e.g., the alimentary canal, nephridia, nervous system, and vascular system. Moreover, some external characters, such as the prostomia, dorsal pores, setae, and genital markings, are also valuable in species identification (Gates 1972; Blakemore 2002). Besides these characters, body size and colouration are two external characters commonly and extensively used in the taxonomy of many animal taxa. However, in earthworms these two characters are evolutionarily less conservative, subject to environmental influence, and intraspecifically variable. In addition, they are easily affected by the methods of 
sample processing and preservation. That is why the use of body size and colouration has been limited in earthworm species identification (Gates 1972; Blakemore 2002).

Amynthas wulinensis Tsai, Shen \& Tsai, 2001, a member of the pheretimoid earthworms within the Megascolecidae, is an octothecate montane earthworm reported from central Taiwan. Its body size, colouration, and genital markings vary among different collection sites and elevations. The 63 specimens reported from central Taiwan have variable postclitellar genital papillae but no preclitellar ones (Tsai et al. 2001). Their body length varies from $6.3 \mathrm{~cm}$ in some specimens collected at lower elevations to $17.4 \mathrm{~cm}$ in some collected at higher elevations (Tsai et al. 2001). The species may be more variable still: some newly collected specimens from northern and central Taiwan have lengths exceeding $20 \mathrm{~cm}$, greater than those reported in the original description, and most of them, though not all, have preclitellar genital papillae (H.-P. Shen personal communication; authors' personal observation). Additional newly collected specimens from south-central Taiwan are similar to those reported from Nanshan Creek, Mt. Beidongyan, and Meifeng (Tsai et al. 2001), but have preclitellar genital papillae (authors' personal observation). Moreover, most, if not all, of the large live specimens, i.e., specimens with body lengths exceeding $20 \mathrm{~cm}$, show quite dark pigmentation on the setal annuli, resulting in a striped appearance. This unique body colouration has never been observed in smaller live specimens. Collectively, these differences in body size, colouration, and genital markings may be the result of environmental variation in different habitats. Alternatively, specimens with different morphological character states may belong to different genetic lineages or even different species. Further evaluation of this problem requires information from studies based on molecular approaches, such as DNA sequence analyses.

Among the published papers, only four earthworm studies focused on genetic differentiation between congeneric species or between different populations of a single species using DNA sequence analyses. Jamieson et al. (2002) used rDNA data to separate some congeneric species of Megascolecidae. Heethoff et al. (2004) used cytochrome $c$ oxidase subunit II (COII) gene sequences to analyse the genetic differentiation between two parthenogenetic populations of the lumbricid earthworm Octolasion tyrtaeum (Savigny, 1826) differing in body size. Pérez-Losada et al. (2005) used 28S rRNA and COI gene sequences to verify that two earthworms, Eisenia fetida (Savigny, 1826) and E. andrei (Bouché, 1972), are both valid phylogenetic species. Chang and Chen (2005) used cytochrome $c$ oxidase subunit I (COI) gene sequences to re-evaluate the taxonomic status of two sibling pheretimoid earthworms, Metaphire formosae (Michaelsen, 1922) and
M. yuhsii (Tsai, 1964). They also analysed the genetic differentiation between two different populations of M. yuhsii. These four studies show that molecular approaches are applicable and very useful to research on the taxonomy and intraspecific variation of earthworms. In the present study, we attempt to re-evaluate the taxonomic status of $A$. wulinensis with the aid of DNA sequence analysis. We also discuss the feasibility of applying body size and colouration in species identification.

\section{Materials and methods}

\section{Sample collection and preservation}

Samples of $A$. wulinensis were collected from various localities in Taiwan. The earthworms were anesthetised in a $10 \%$ ethanol solution. Some muscle tissues were isolated and preserved in a $70 \%$ or $95 \%$ ethanol solution for DNA extraction. The residual earthworm samples were fixed in $10 \%$ formalin and preserved in a $70 \%$ ethanol solution. Some other Amynthas species collected in Taiwan were treated using the same procedure for the phylogenetic analysis. The earthworm specimens are deposited at the Institute of Zoology, National Taiwan University, Taipei.

\section{DNA extraction, PCR, and DNA sequencing}

Muscle tissues were washed with distilled water, homogenised in liquid nitrogen, and digested in digestion buffer $(10 \mathrm{mM}$ Tris- $\mathrm{HCl}, 2 \mathrm{mM}$ dihydrate EDTA, $10 \mathrm{mM} \mathrm{NaCl}, 10 \mathrm{mg} / \mathrm{ml}$ DTT, $1 \%$ SDS, and $0.4 \mathrm{mg} / \mathrm{ml}$ proteinase $\mathrm{K}$ ) at $50^{\circ} \mathrm{C}$ for $15-30 \mathrm{~min}$. Total DNA was extracted from the digested tissue-buffer solution with a standard phenol/chloroform extraction method (Palumbi et al., 1991). The ethanol-precipitated DNA was dissolved in distilled water, checked with $1.0 \%$ agarose gel electrophoresis, and stored at $-20^{\circ} \mathrm{C}$.

A 626-bp mitochondrial cytochrome $c$ oxidase subunit I (COI) DNA fragment was amplified using the universal primers LCO1490 (5'-GGT CAA CAA ATC ATA AAG ATA TTG G-3') and HCO2198 (5'-TAA ACT TCA GGG TGA CCA AAA AAT CA-3') (Folmer et al. 1994). PCR amplifications were carried out in a $50 \mu \mathrm{l}$ total volume, using 1 cycle at $94^{\circ} \mathrm{C}$ for $1 \mathrm{~min}$, followed by 35 cycles of denaturation for $30 \mathrm{~s}$ at $94^{\circ} \mathrm{C}$, annealing for $30 \mathrm{~s}$ at $54^{\circ} \mathrm{C}$, and extension for $50 \mathrm{~s}$ at $72{ }^{\circ} \mathrm{C}$, with a final extension at $72{ }^{\circ} \mathrm{C}$ for $10 \mathrm{~min}$.

The PCR products were checked using $1.0 \%$ agarose gel electrophoresis and sequenced in both directions using the same primers as in the PCR. Sequencing was performed with the ABI PRISM BigDye Terminator Cycle Sequencing Ready Reaction Kit, V3.1 (Applied Biosystems, CA, USA). Products were analysed with a 
ABI 3730 XL DNA analyzer (Applied Biosystems). The computer base calling was double-checked by eye.

\section{Sequence alignment and phylogenetic analyses}

The sequence was checked by aligning the sequencing results with the COI full sequence of Lumbricus terrestris (GenBank accession no. U24570) using the default settings of Clustal X 1.81 (Thompson et al. 1997).

The sequence of Pontodrilus litoralis was retrieved from GenBank (Table 1) and used as an outgroup in the phylogenetic analyses. All sequences analysed were aligned using the default settings of Clustal X 1.81. A homologous fragment of $626 \mathrm{bp}$ of the COI sequence was used in this study. The sequences obtained were submitted to GenBank (see Table 1). Neighbour-joining (NJ) analyses were performed using MEGA 2.1 (Kumar et al. 2001) with Kimura's (1980) two-parameter model. Maximum-parsimony (MP) analyses were performed using PAUP 4.0b10 (Swofford 2000) with heuristic searches, random starting trees, 100 random additions of sequences, and TBR branch swapping. Bootstrapping with 1000 pseudo-replicates for the NJ and MP analyses was used to examine the robustness of the clades and their phylogenetic relationships.

\section{Morphological comparisons}

The characters described in the original description of A. wulinensis (Tsai et al. 2001), such as body length, clitellum width, spermathecae, male pores, testes, setae, and genital markings, were used to compare the intraspecific clades revealed in the phylogenetic analyses.

\section{Results}

\section{Phylogenetic analyses}

The samples used in the phylogenetic analyses and the corresponding GenBank accession numbers of the COI sequences are listed in Table 1 . In the 626-bp COI

Table 1. Samples used in the phylogenetic analyses, and corresponding GenBank accession numbers; asterisks indicate sequences retrieved from GenBank

\begin{tabular}{|c|c|c|c|}
\hline OTUs & Locality & Sample no. & Accession no. \\
\hline \multirow[t]{9}{*}{ Amynthas wulinensis s.l. (clade A) } & Wulai, Taipei County & B0415 & DQ224166 \\
\hline & Wulai, Taipei County & B0416 & DQ224167 \\
\hline & Wulai, Taipei County & B0417 & DQ224168 \\
\hline & Wulai, Taipei County & B0418 & DQ224169 \\
\hline & Meishan, Chiayi County & B2802 & DQ224170 \\
\hline & Meishan, Chiayi County & B2803 & DQ224171 \\
\hline & Meishan, Chiayi County & B2804 & DQ224172 \\
\hline & Meishan, Chiayi County & B2805 & DQ224173 \\
\hline & Meishan, Chiayi County & B2806 & DQ224174 \\
\hline \multirow[t]{8}{*}{ A. wulinensis s.1. (clade B) } & Kunyang, Nantou County & B2703 & DQ224175 \\
\hline & Kunyang, Nantou County & B2704 & DQ224176 \\
\hline & Kunyang, Nantou County & B2705 & DQ224177 \\
\hline & Kunyang, Nantou County & B2706 & DQ224178 \\
\hline & Kunyang, Nantou County & B2707 & DQ224179 \\
\hline & Kunyang, Nantou County & B2708 & DQ224180 \\
\hline & Meifeng, Nantou County & B2901 & DQ224181 \\
\hline & Meifeng, Nantou County & B2902 & DQ224182 \\
\hline \multirow[t]{5}{*}{ A. wulinensis s.1. (clade C) } & Meishan, Chiayi County & B2903 & DQ224183 \\
\hline & Meishan, Chiayi County & B2904 & DQ224184 \\
\hline & Meishan, Chiayi County & B2905 & DQ224185 \\
\hline & Meishan, Chiayi County & B2906 & DQ224186 \\
\hline & Meishan, Chiayi County & B2907 & DQ224187 \\
\hline A. tayalis & Wulai, Taipei County & & AY962185* \\
\hline A. binoculatus & Baoshan, Hsinchu County & & AY962184* \\
\hline A. aspergillus & Lienhuachih, Nantou County & & DQ224188 \\
\hline A. polyglandularis & Wulai, Taipei County & & DQ224189 \\
\hline A. corticis & Taipei City & & DQ224190 \\
\hline A. robustus & Taipei City & & DQ224191 \\
\hline Pontodrilus litoralis & & & AF003256* \\
\hline
\end{tabular}


sequence, no insertions or deletions were found. From 22 individuals of $A$. wulinensis, 16 haplotypes of the COI gene were observed: seven, six, and three haplotypes belonged to clades $\mathrm{A}, \mathrm{B}$, and $\mathrm{C}$ in the phylogenetic analyses, respectively (see below). The genetic distances among different clades and other Amynthas species are listed in Table 2. The average genetic distances between each pair of clades $\mathrm{A}, \mathrm{B}$, and $\mathrm{C}$ of $A$. wulinensis were equivalent to the interspecific genetic distances between other Amynthas species. Genetic distances between any pair of individuals within each of clades A, B, and C were $0-14.6 \%, 0-9.9 \%$, and $0-0.8 \%$, respectively. All of these values were smaller than the genetic distances between each pair of the three clades.

For the 626-bp sequence, 244 variable sites were observed, among which 216 were parsimony informative. The phylogenetic analyses resulted in a strictconsensus tree from the three MP trees equalling 799 steps (Fig. 1), with a consistency index (CI) of 0.4731, a homoplasy index (HI) of 0.5269 , a retention index (RI) of 0.7455 , and a rescaled consistency index (RC) of 0.3527 . The NJ tree had a topology and bootstrap values similar to the strict-consensus MP tree (Fig. 1). The two trees strongly indicate $A$. wulinensis sensu lato as being non-monophyletic, composed of three separate monophyletic clades A, B, and C (respective bootstrap values in the NJ and MP trees: 99 and 91 for clade A, 100 and 100 for clade B, 100 and 100 for clade C). The presence of three clades and the amounts of sequence divergence between them are clear evidence that specimens formerly identified as A. wulinensis belong to a species complex composed of three different species corresponding to clades $\mathrm{A}, \mathrm{B}$, and $\mathrm{C}$.

\section{Taxonomic section}

According to the morphology and collection sites, clade $\mathrm{B}$ in the phylogenetic analyses is A. wulinensis Tsai

Table 2. Pairwise comparisons of Amynthas wulinensis and other Amynthas species in Taiwan by Kimura's two-parameter distance

\begin{tabular}{lllllllll}
\hline Otus & AwuA & AwuB & AwuC & Apo & Ata & Abi & Aas & Aro \\
\hline AwuB & 0.193 & & & & & & & \\
AwuC & 0.223 & 0.208 & & & & & & \\
Apo & 0.209 & 0.208 & 0.197 & & & & & \\
Ata & 0.190 & 0.188 & 0.152 & 0.198 & & & & \\
Abi & 0.204 & 0.204 & 0.198 & 0.208 & 0.198 & & & \\
Aas & 0.225 & 0.211 & 0.244 & 0.202 & 0.214 & 0.225 & & \\
Aro & 0.186 & 0.179 & 0.214 & 0.220 & 0.205 & 0.201 & 0.169 & \\
Aco & 0.179 & 0.188 & 0.203 & 0.198 & 0.168 & 0.207 & 0.191 & 0.168
\end{tabular}

Awu $\mathrm{A}=$ clade $\mathrm{A}$ of $A$. wulinensis $; \mathrm{AwuB}=$ clade $\mathrm{B}$ of $A$. wulinensis; $\mathrm{AwuC}=$ clade $\mathrm{C}$ of $A$. wulinensis; $\mathrm{Apo}=$ A. polyglandularis; $\mathrm{Ata}=A$. tayalis; $\mathrm{Abi}=A$. binoculatus; $\mathrm{Aas}=A$. aspergillus; $\mathrm{Aro}=A$. robustus; Aco $=$ A. corticis. et al., 2001, whereas clades $\mathrm{A}$ and $\mathrm{C}$ are new species. The two new species are described below.

\section{Amynthas lini sp. n. (Fig. 2)}

\section{Etymology}

The species epithet is given in honour of the Taiwanese zoologist Dr. Yao-Sung Lin, who is promoting earthworm studies in Taiwan.

\section{Material}

\section{Type material}

Holotype: Mature (clitellate) specimen, dissected; Taiwan, Taipei Co., Wulia, 24 November 2001, C.-H. Chang (cat. no. 14-02815; Institute of Zoology, National Taiwan University, Taipei). Paratypes (all mature (clitellate) specimens, dissected): Two specimens; data as for holotype (14-02801 and 14-02814). One specimen; as holotype, except 1 August 2001 (14-02802). One specimen; as holotype, except 9 June 2000, C.-E. Lee (14-7292). One specimen; Taipei Co., Hsintien, 26 October 2000, S.-P. Wu (14-7291). One specimen; northern Taiwan, Ilan Co., Jiaushi, 18 May 2002, I.-H. Chen (14-03864). One specimen; northwestern Taiwan, Taoyuan Co., region surrounding Shihmen Reservoir, 14 December 2002, I.-H. Chen (14-05451).

\section{Other material examined (all mature (clitellate) specimens)}

One specimen (dissected); Taipei City, 9 August 2000, C.-H. Chang (14-00867). One specimen (dissected); Wulai, 1 August 1999, S.-P. Wu (14-00870). One specimen (dissected); central Taiwan, Nantou Co., Meifeng, 16 September 1999, I.-H. Chen (14-02463). Two specimens; Wulai, 1 August 2001, C.-H. Chang (14-02803 and 14-02805). One specimen; Jiaushi, 18 May 2002, I.-H. Chen (14-03885). One specimen; northcentral Taiwan, Hsinchu Co., Taoshan, 4 March 2003, I.-H. Chen (14-05889). One specimen; Hsinchu Co., Jiuchongping, 24 July 2003. I.-H. Chen (14-06552). One specimen; central Taiwan, Nantou Co., Kunyang, 22 October 2004, C.-H. Chang (14-07249). Two specimens; south-central Taiwan, Chiayi Co., Meishan, 6 December 2003, C.-H. Chang (14-07293 and 14-07294). One specimen (dissected); Meifeng, 5 October 2002, I.-H. Chen (14-07295). Two specimens; Meishan, 24 October 2004, C.-H. Chang (14-07254 and 14-07255).

\section{External characters}

Length $212-254 \mathrm{~mm}$; clitellum width $7.0-9.0 \mathrm{~mm}$; segment number 117-129; number of annuli per segment 1 in $\mathrm{I}-\mathrm{V}, 3$ in VI and beyond; prostomium epilobous; setae 20-26 in V, 33-45 in VII, 49-57 in X, 

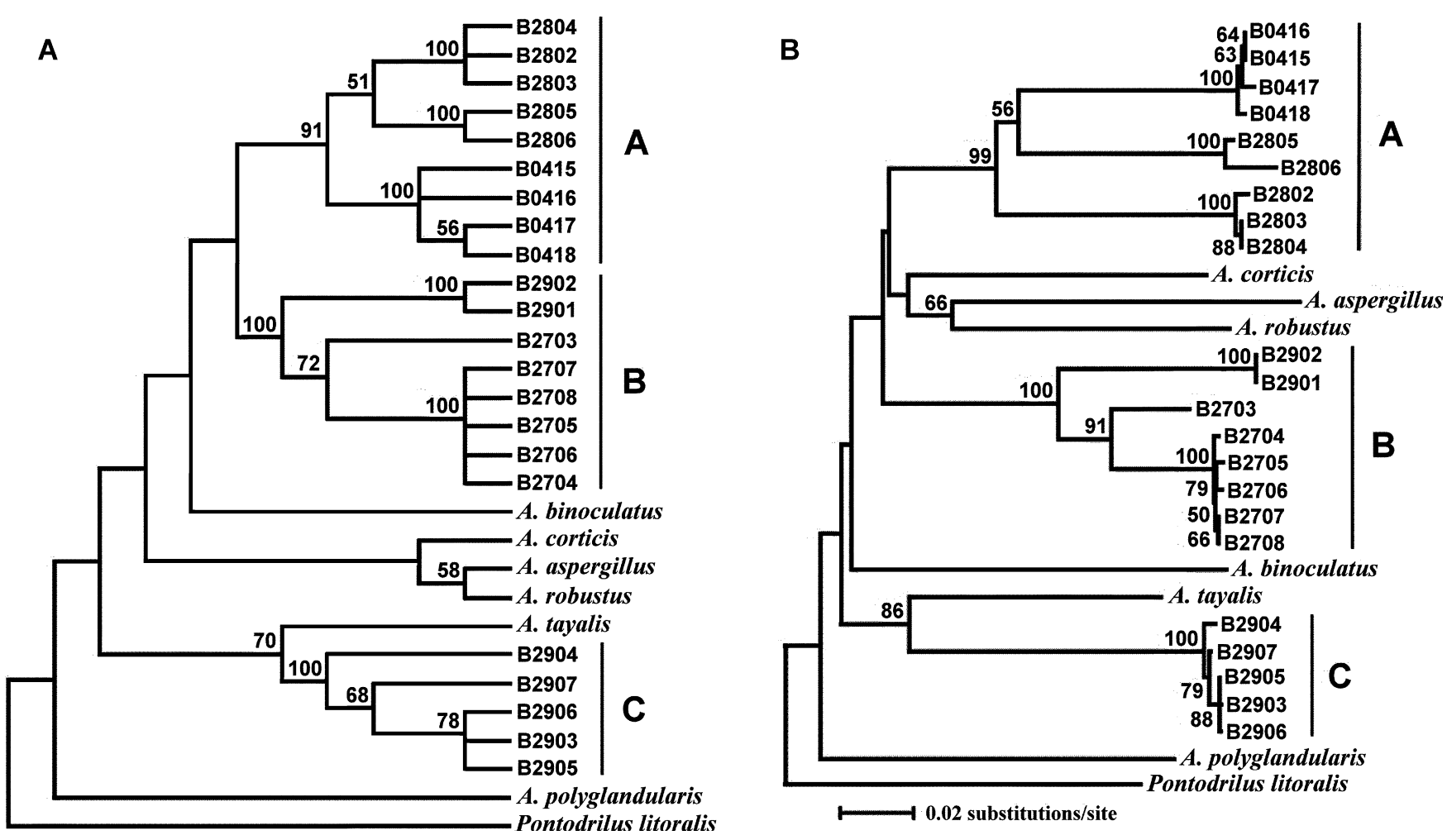

Fig. 1. Phylogenetic trees of Amynthas wulinensis and some congeneric species, based on DNA sequences of the mitochondrial COI gene. (A) Strict consensus of three maximum-parsimony trees reconstructed using heuristic searches, 100 random additions of sequences, and TBR branch swapping. (B) Neighbour-joining tree reconstructed using Kimura's two-parameter model. Bootstrap support values $>50$ indicated at nodes. See text on clades (A), (B) and (C).

8-17 between male pores; first dorsal pore in 12/13; clitellum XIV-XVI, smooth; setae and dorsal pores absent.

Spermathecal pores four pairs in 5/6-8/9, ventrolaterally. Distance between paired spermathecal pores about 0.40 body circumference ventrally. Genital papillae present or absent. When present, papillae presetal, postsetal, or both. Presetal papillae 1-4 pairs in VII-X. Each papilla large, round, disc-like; distance between paired genital papillae about $0.10-0.30$ body circumference ventrally. Sometimes only 1 papilla present on some segments. Postsetal papillae two pairs in VII and VIII, similar to presetal ones but smaller, distance between paired genital papillae about 0.40 body circumference ventrally. Sometimes only 1 papilla present on some segments. Female pore single, medioventrally in XIV. Male pores paired in XVIII, lateroventrally, distance between pores about 0.33 body circumference ventrally. Porophores round or oval on setal line, with a concave centre surrounded by 2 or 3 circular folds. Fold lines on some specimens parallel with setal line. Genital papillae postsetal, paired in XIX. Two specimens with an additional pair in XVII. One specimen with an additional pair in XX. Two specimens with 2 additional pairs in XVII and XX. Each papilla oval, with a concave centre surrounded by a few circular folds.
Preserved specimens dark brown on dorsum and around clitellum, light yellow on venter and setal lines, forming a striped or banded appearance, a dark brown circular band, and a light yellow one in sequence.

\section{Internal characters}

Septa 5/6-7/8 thickened, $8 / 9$ and $9 / 10$ absent, 10/ $11-13 / 14$ greatly thickened. Gizzard round in $\mathrm{X}$, almond-coloured. Intestine enlarged from XV. Intestinal caeca paired in XXVII, simple, surface slightly folded with the septa, grey-coloured, extending to XXIII or XXII. Lateral hearts enlarged in XI-XIV.

Spermathecae four pairs in VI-IX, with a short thick stalk about $0.45 \mathrm{~mm}$ long. Ampulla round, light yellow, about $3.00 \mathrm{~mm}$ in diameter. Spermathecal diverticula present, with a small oval seminal chamber of $2.07 \mathrm{~mm}$ and a slender, straight stalk of $1.69 \mathrm{~mm}$. Nephridia tufted, attached to post-segmental septa, surrounding segmental chambers anterior to septum 6/7. No nephridia on spermathecal ducts. Ovaries paired in XIII, medioventral, close to septum 12/13.

Testes paired in $\mathrm{X}$ and $\mathrm{XI}$, small, irregular, light yellow. Seminal vesicles paired in XI and XII, large, white or light brown. Prostate glands paired in XVIII, large, almond-coloured, extending anteriorly to XVI, with a 
A

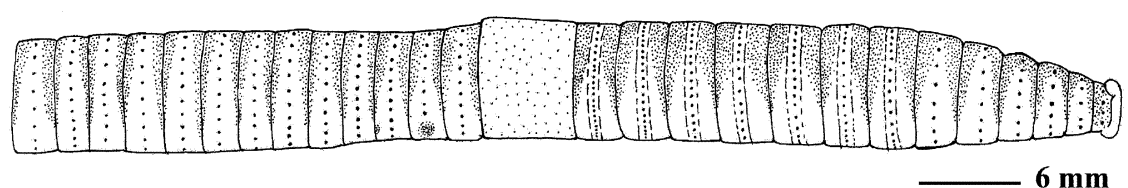

B

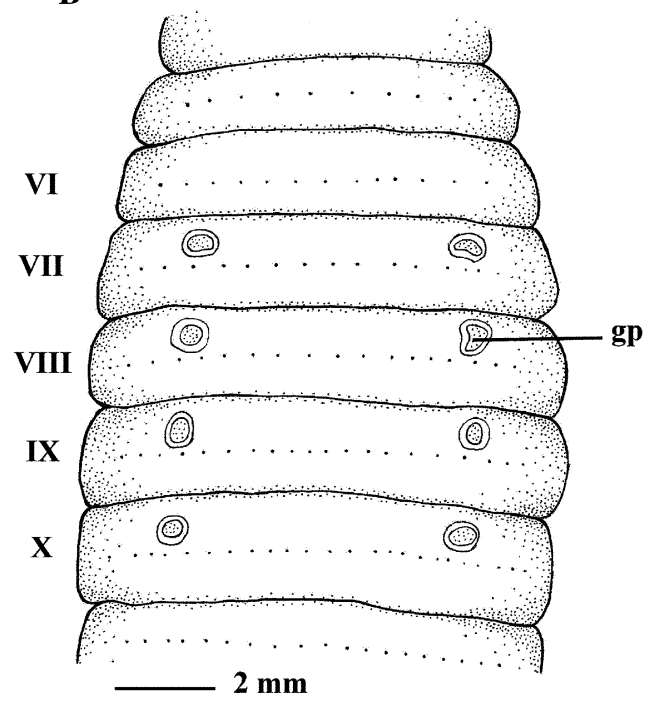

C

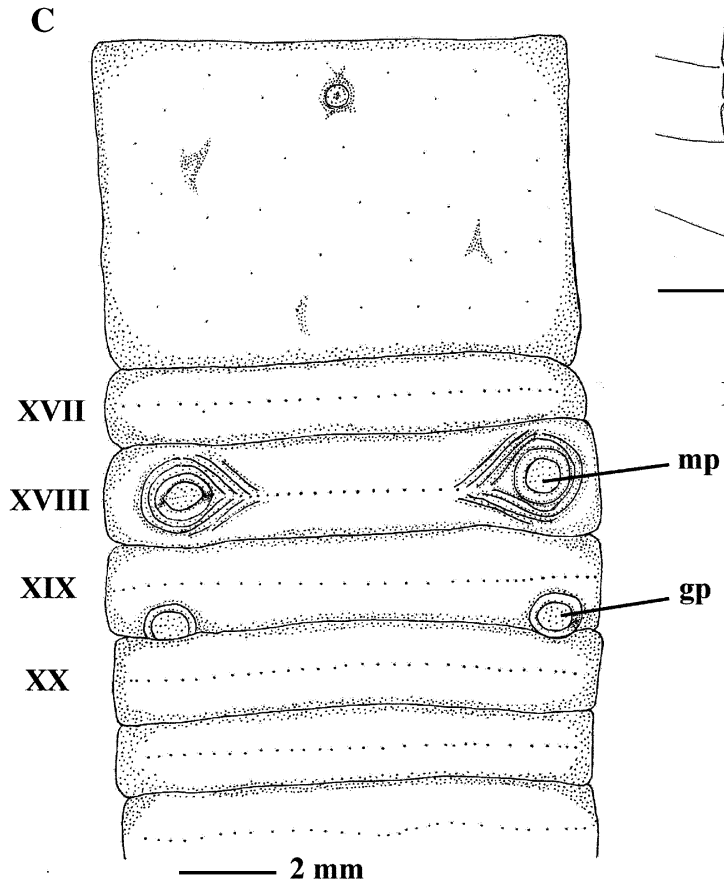

D

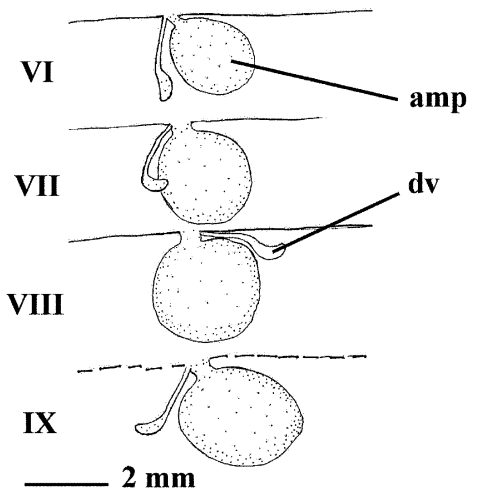

G

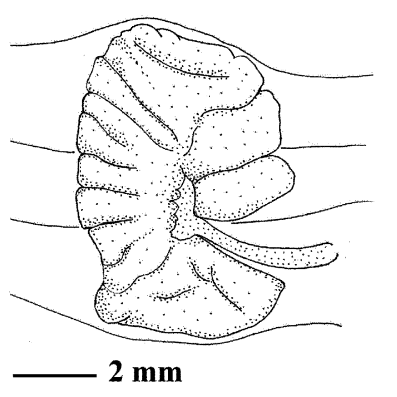

F
$\mathbf{E}$

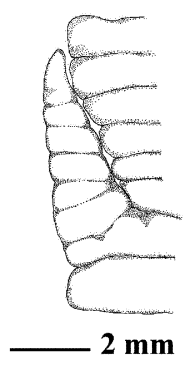

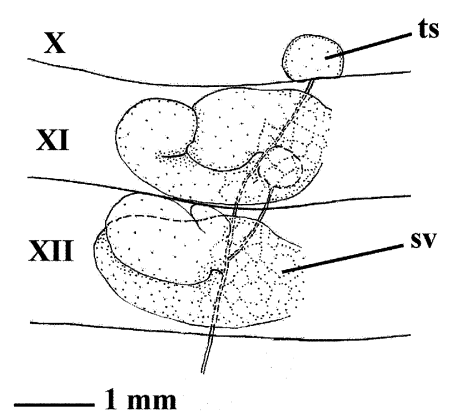

Fig. 2. Amynthas lini, morphology. (A) Lateral view of anterior body. (B) Ventral view of spermathecal pore region; gp = genital pad. (C) Male pore area; $g p=$ genital pad, $\mathrm{mp}=$ male pore. (D) Left spermathecae; amp = ampulla, $\mathrm{dv}=$ diverticulum. (E) Left caecum. (F) Left testis sacs and seminal vesicles; ts $=$ testis sac, $\mathrm{sv}=$ seminal vesicle. (G) Left prostate gland.

thick straight duct (Fig. 2). Accessory glands paired in XIX, with positions corresponding to external papillae.

\section{Localities and habitats}

Amynthas lini sp. n. is distributed in mountainous areas of northern and central Taiwan, at elevations from 400 to $3000 \mathrm{~m}$ (Fig. 4). Animals usually crawl out onto the ground on rainy days and can often be found in drainage ditches along roads.

\section{Amynthas meishanensis sp. n. (Fig. 3)}

\section{Etymology}

The species epithet, to be treated as an adjective, refers to the type locality. 


\section{Material}

\section{Type material}

Holotype: Mature (clitellate) specimen, dissected; south-central Taiwan, Chiayi Co., Meishan, 24 October 2004, C.-H. Chang and Y.-H. Lin (cat. no. 14-07290; Institute of Zoology, National Taiwan University, Taipei). Paratypes: Three mature (clitellate) specimens (one dissected); same data as holotype (14-07285, 1407288, and 14-07289).

\section{Other material examined}

Ten mature (clitellate) specimens (7 dissected); same data as holotype (14-07258-14-07264, 14-07284, 1407286, and 14-07287).

\section{External characters}

Length $38-65 \mathrm{~mm}$; clitellum width $2.7-3.5 \mathrm{~mm}$; segment number 51-113; one annulus per segment on all segments; prostomium epilobous; setae $27-31$ in V, 35-42 in VII, 41-48 in X, 5-8 between male pores; first dorsal pore in $10 / 11$; clitellum XIV-XVI, smooth; setae and dorsal pores absent.

Spermathecal pores four pairs in 5/6-8/9, laterally. Distance between paired spermathecal pores about 0.5 body circumference ventrally. Two pairs of papillae present in each of VII and VIII, 1 presetal and 1 postsetal. Some specimens lacking papillae to varying extent; 1 specimen without spermathecal papillae. Some specimens have 1 additional postsetal papilla in VI. Each papilla small, round; distance between paired genital papillae about 0.20 body circumference ventrally. Female pore single, medioventral in XIV. Male pores paired in XVIII, lateroventrally; distance between pores about 0.35 body circumference ventrally. Porophores round or oval on setal line, surrounded by 5-7 circular folds. Genital papillae postsetal, paired in XVII and XIX. One specimen with only the left papilla in XIX. Two specimens with additional papillae in XX: one with a pair, the other with only the right one. Each papilla small, oval, with concave centre.

Preserved specimens reddish brown on dorsum, light yellowish brown on venter.
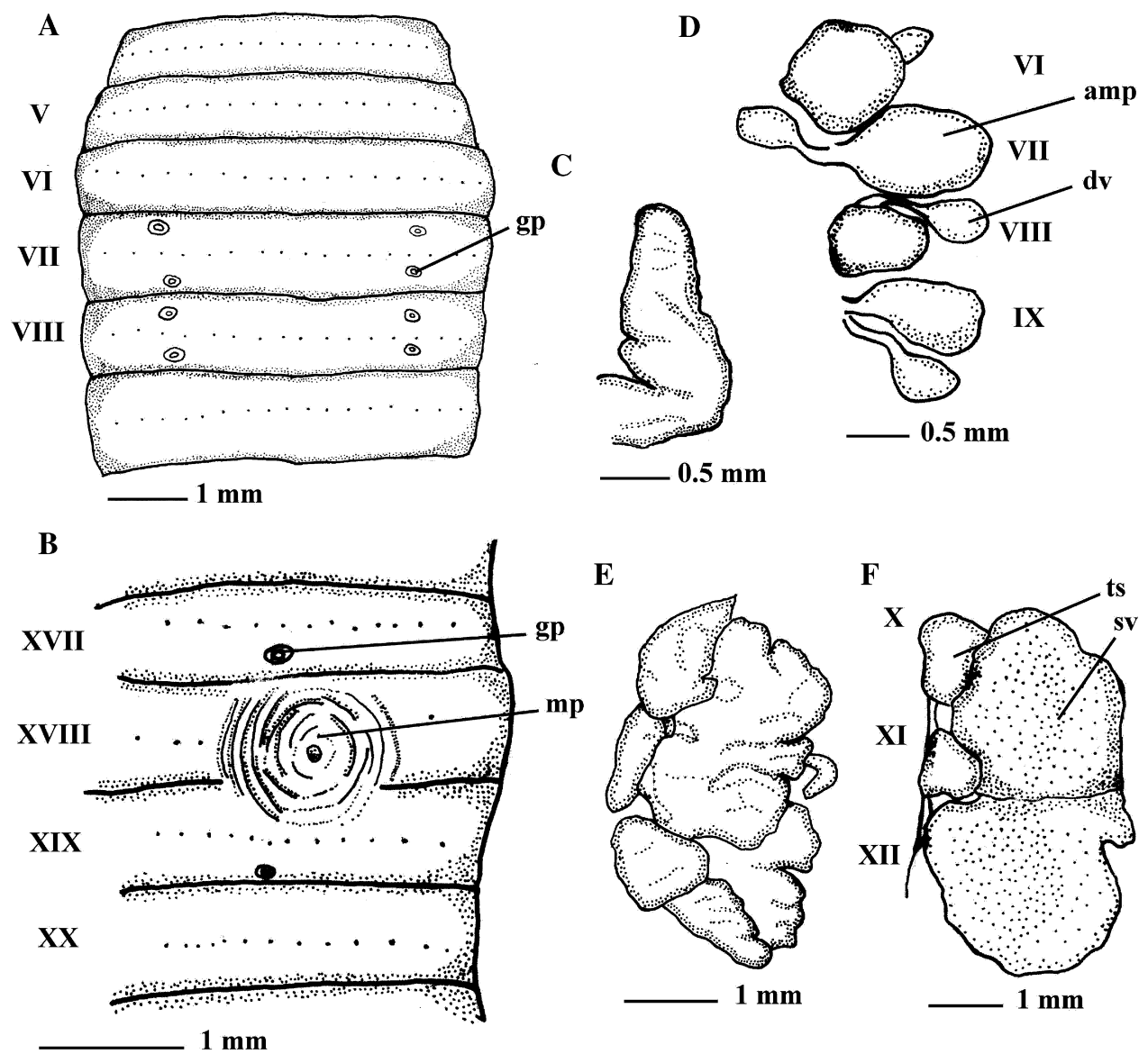

Fig. 3. Amynthas meishanensis, morphology. (A) Ventral view of spermathecal pore region; gp = genital pad. (B) Left male pore area; $\mathrm{gp}=$ genital pad, $\mathrm{mp}=$ male pore. (C) Right caecum. (D) Right spermathecae; amp = ampulla, dv = diverticulum. (E) Right prostate gland. (F) Left testis sacs and seminal vesicles; ts = testis sac, sv = seminal vesicle. 


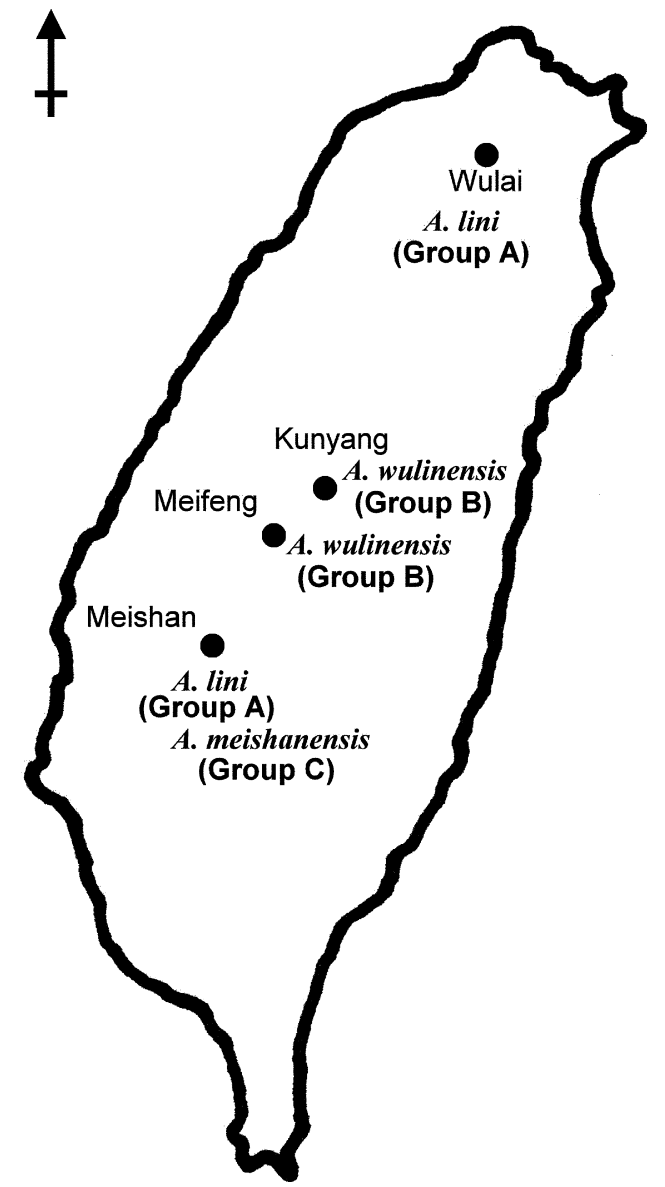

Fig. 4. Collection sites of the Amynthas wulinensis species complex in Taiwan.

\section{Internal characters}

Septa 8/9 and 9/10 absent, 10/11-13/14 thickened. Gizzard round in VII-X. Intestine enlarged from XV. Intestinal caeca paired in XXVII, simple, extending to XXIV. Lateral hearts enlarged in X-XIII.

Spermathecae four pairs in VI-IX, with a short stalk about $0.2 \mathrm{~mm}$ long and a peach-shaped or oval ampulla about $0.6-1.0 \mathrm{~mm}$ long. Spermathecal diverticula present, with a peach-shaped seminal chamber and a straight stalk about as long as seminal chamber. No nephridia on spermathecal ducts. Ovaries paired in XIII, medioventral, close to septum 12/13.

Testes paired in X and XI, small, irregular. Seminal vesicles paired in XI and XII, large. Prostate glands paired in XVIII, large, extending anteriorly to XVII and posteriorly to $\mathrm{XX}$, with a thick duct.

\section{Localities and habitats}

Amynthas meishanensis sp. n. inhabits secondary broadleaf forests in central Taiwan, at elevations around $600 \mathrm{~m}$ (Fig. 4). It is often found in ditches without water but filled with soil in this mountainous area.

\section{Remarks}

Amynthas lini and A. meishanensis correspond to clades A and C, respectively, in the phylogenetic analyses. They are morphologically similar to $A$. wulinensis s. str.; the

Table 3. Morphological comparison of Amynthas wulinensis, A. lini n. sp., and A. meishanensis n. sp. according to original descriptions

\begin{tabular}{llll}
\hline & A. wulinensis & A. lini & A. meishanensis \\
\hline Body length (mm) & $63-174$ & $212-254$ & $38-65$ \\
Clitellum width (mm) & $5.6-6.1^{\mathrm{a}}$ & $7.0-9.0$ & $2.7-3.5$ \\
Number of segments & $70-132$ & $117-129$ & $51-113$ \\
First dorsal pore position & $11 / 12$ & $12 / 13$ & $10 / 11$ \\
Prostomium & Epilobous & Epilobous & Epilobous \\
Secondary segmentation & 3 annuli after VI & 3 annuli after VI & 1 annulus for all segments \\
Setae & & & $27-31$ \\
V & ND & $20-26$ & $35-42$ \\
VII & $28-45$ & $33-45$ & $41-48$ \\
X & ND & $49-57$ & ND \\
XX & $33-69$ & ND & $5-8$ \\
Between male pores & $8-13$ & $8-17$ & 4 pairs \\
Number of spermathecae & 4 pairs & 4 pairs & 10 and 11 \\
Position of testes & 10 and 11 & 10 and 11 & 11 and 12 \\
Position of seminal vesicles & 11 and 12 & 11 and 12 & $17-20$ \\
Position of prostate glands & $15-20$ & $17-21$ & Absent or 6-8 \\
Position of preclitellum papillae & Absent & Absent or $7-10$ & 17,19 and 20 \\
Position of postclitellum papillae & 17,19 and 20 & 17,19 and 20 & \\
\hline
\end{tabular}

ND: no data.

${ }^{\text {a }}$ Data from reported non-type material, not available in original description. 
three species form the A. wulinensis species complex. They are holandric, octothecate earthworms belonging to the corticis species group of the genus Amynthas (Sims and Easton 1972). Most morphological characters do not differ between the three species (Table 3). However, the numbers of setae between the male pores are generally higher in A. lini and A. wulinensis than in A. meishanensis, but they still overlap among the three species. The male pores of the three species are quite similar, but those of A. meishanensis have more circular folds around the porophores, and the associated genital papillae are comparatively smaller (Figs. 2 and 3). Spermathecal papillae are often present in $A$. lini and A. meishanensis, but they are absent in $A$. wulinensis. The arrangement of these papillae is more regular in A. meishanensis than in $A$. lini, and their positions differ (Table 3). Body sizes, including body length and clitellum width, also differ among the three species. A. lini, a species locally called 'snake earthworms' because of its large body size, is larger than the other two species; A. meishanensis is slightly smaller than $A$. wulinensis. In live specimens, the striped or banded appearance of $A$. lini is a remarkable feature, making the species easily distinguishable from the other two species.

\section{Discussion}

Although included in character descriptions of earthworms, body size and colouration are seldom regarded as species-diagnostic characters because they tend to vary intraspecifically (Gates 1972; Blakemore 2002). The use of these two characters in earthworm taxonomy is also compromised of the procedures of sample processing. Because earthworms are soft-bodied, different concentrations of alcohol used in sample anesthetisation cause different degrees of muscle contraction or relaxation, which obviously affects the measurable body length and width of earthworm specimens. Even when routinely using $10 \%$ alcohol, the different sample treatments before fixation or preservation also cause differences in body biometry. On the other hand, the use of $5-10 \%$ formalin for fixation and $70 \%$ alcohol for preservation both result in the decolouration of earthworm specimens. In addition, with these treatments, the transparent portions of specimens usually become whitish; and the so-called 'alcoholic browning' occurs in specimens after long-term preservation in alcohol (Gates 1972). These make most specimens look similar in colour, whether they are conspecific or not.

The three species of the A. wulinensis species complex, A. lini n. sp., A. meishanensis n. sp., and A. wulinensis, are morphologically similar. For this reason, they were formerly treated as a single species. However, after comparing larger numbers of specimens, we find that the combined use of genital papillae, body size and colouration can lead to correct identifications within the A. wulinensis species complex. Actually, when the target specimens have no preclitellum genital papillae, body size and colouration are the most important characters for distinguishing between $A$. wulinensis and A. lini.

The use of body size and/or colouration as diagnostic characters is rare in earthworm taxonomy. However, a famous case is the distinction between E. fetida and E. andrei. Concerning morphology, E. fetida has a striped or banded appearance whereas $E$. andrei is uniformly reddish, but aside from this difference in colouration, the two species are indistinguishable (Domínguez et al. 2005). This similarity caused a 30year discussion on whether or not the two colour morphs are conspecific. Now it is clear that they are indeed two different species (Roch et al. 1980; Valembois et al. 1982; Domínguez et al. 2005; Pérez-Losada et al. 2005), and that many specimens treated as E. fetida in ecotoxicological studies or organic waste management actually represent $E$. andrei or a mixture of both species (Domínguez et al. 2005). Besides the instances of the $A$. wulinensis species complex and E. fetida/E. andrei, we believe that body size and colouration may also be useful in species identification in other species complexes, in which similar species are hard to differentiate with the traditionally used characters.

Undoubtedly, standardised methods of comparing body size and colouration for earthworms are currently unavailable. When making body size comparisons, most earthworm taxonomists use body length and/or width, which can vary even within a specimen. Comparisons of colouration are usually based on some imprecise terms of colour description, such as 'bluish brown', 'reddish grey', etc. These imprecise treatments of body size and colouration make it difficult to compare these characters reported from various published studies and to use them for species identification. For both purposes, further studies on developing standardised protocols to measure and record body size and colouration are necessary.

\section{Acknowledgements}

$\mathrm{We}$ are grateful to C.-E. Lee and S.-P. Wu for collecting earthworm specimens. We also thank Dr. C.-F. Tsai and H.-P. Shen for their useful suggestions on earthworm taxonomy.

\section{References}

Blakemore, R.J., 2002. Cosmopolitan Earthworms - An EcoTaxonomic Guide to the Peregrine Species of the World, first CD ed. VermEcology, Kippax, ACT, Australia.

Chang, C.-H., Chen, J.-H., 2005. Taxonomic status and intraspecific phylogeography of two sibling species of 
Metaphire (Oligochaeta: Megascolecidae) in Taiwan. Pedobiologia 49, 591-600.

Domínguez, J., Velando, A., Ferreiro, A., 2005. Are Eisenia fetida (Savigny, 1826) and Eisenia andrei Bouché, 1972 (Oligochaeta, Lumbricidae) different biological species? Pedobiologia 49, 81-87.

Folmer, O., Back, M., Hoeh, W., Lutz, R., Vrijenhoek, R., 1994. DNA primers for amplification of mitochondrial cytochrome $c$ oxidase subunit I from diverse metazoan invertebrates. Mol. Mar. Biol. Biotechnol. 3, 294-299.

Gates, G.E., 1972. Burmese earthworms, an introduction to the systematics and biology of Megadrile oligochaetes with special reference to South-East Asia. Trans. Am. Philos. Soc. 62, 1-326.

Heethoff, M., Etzold, K., Scheu, S., 2004. Mitochondrial COII sequences indicate that the parthenogenetic earthworm Octolasion tyrtaeum (Savigny, 1826) constitutes of two lineages differing in body size and genotype. Pedobiologia 48, 9-13.

Jamieson, B.G.M., Tillier, S., Tillier, A., Justine, J.-L., Ling, E., James, S., McDonald, K., Hugall, A.F., 2002. Phylogeny of the Megascolecidae and Crassiclitellata (Annelida, Oligochaeta): combined versus partitioned analysis using nuclear (28S) and mitochondrial (12S, 16S) rDNA. Zoosystema 24, 707-734.

Kimura, M., 1980. A simple method for estimating evolutionary rates of base substitutions through comparative studies of nucleotide sequence. J. Mol. Evol. 16, 111-120.

Kumar, S., Tamura, K., Jakobsen, I.B., Nei, M., 2001. MEGA2: molecular evolutionary genetics analysis software. Bioinformatics 17, 1244-1245.
Palumbi, S., Martin, R.A., Romano, S., McMillan, W.O., Stice, L., Grabowski, G., 1991. The Simple Fool's Guide to PCR, version 2. University of Hawaii Zoology Department, Honolulu.

Pérez-Losada, M., Eiroa, J., Mato, S., Domínguez, J., 2005. Phylogenetic species delimitation of the earthworms Eisenia fetida (Savigny, 1826) and Eisenia andrei Bouché, 1972 (Oligochaeta, Lumbricidae) based on mitochondrial and nuclear DNA sequences. Pedobiologia 49, 317-324.

Roch, P., Valembois, P., Lassegues, M., 1980. Biochemical particulars of the antibacterial factor of the two subspecies Eisenia fetida fetida and Eisenia fetida andrei. Am. Zool. 20, 790-794.

Sims, R.W., Easton, E.G., 1972. A numerical revision of the earthworm genus Pheretima auct. (Megascolecidae: Oligochaeta) with the recognition of new genera and an appendix on the earthworms collected by the Royal Society North Borneo Expedition. Biol. J. Linn. Soc. 4, 169-268.

Swofford, D.L., 2000. PAUP 4.0: Phylogenetic Analysis Using Parsimony (and Other Methods). Sinauer, Sunderland, MA.

Thompson, J.D., Gibson, T.J., Plewniak, F., Jeanmougin, F., Higgins, D.G., 1997. The CLUSTAL_X windows interface: flexible strategies for multiple sequence alignment aided by quality analysis tools. Nucleic Acids Res. 25, 4876-4882.

Tsai, C.-F., Shen, H.-P., Tsai, S.-C., 2001. Some new earthworms of the genus Amynthas (Oligochaeta: Megascolecidae) from Mt. Hohuan of Taiwan. Zool. Stud. 40, 276-288.

Valembois, P., Roch, P., Lassegues, M., Davant, N., 1982. Bacteriostatic activity of a chloragogen cell secretion. Pedobiologia 24, 191-197. 